\title{
Kore Savaşı Ekseninde ABD-Çin İlişkilerinin Çin Propaganda Posterleri Üzerinden Analizi
}

\author{
Mustafa KARACA ${ }^{1}$, Mehmet Ali GAZİ ${ }^{2}$ ve Caner ÇAKI ${ }^{3}$
}

$\ddot{O} z$

Çin Halk Cumhuriyeti, 25 Ekim 1950 tarihinde Kore Savaşı'na müdahalede bulunarak, Kuzey Kore'ye askeri yardım göndermişti. Çin'in yardımı ile savaşın kaderi değişmiş ve ABD savaştaki inisiyatifini kaybetmişti. Bu süreçte Çin yönetimi, Çin halkından destek bulabilmek için ABD karşıtı yoğun bir propaganda faaliyetine girmişti. Çin, bu süreçte posterleri etkili bir şekilde propaganda aracı olarak kullanmış ve Çin halkını ABD'ye karşı harekete geçirmek için çalışmıştı. Çalışma kapsamında Çin propagandası tarafından Kore Savaşı'nda kullanılan posterlerde ABD karşıtı hangi öğelere yer verildiği ortaya konulmaya çalışılmıştır. Bu amaçla çalışma kapsamında Uluslararası Sosyal Tarih Enstitüsü'nden amaçlı örneklem metodu kullanılarak seçilen altı propaganda posteri, nitel araştırma yöntemleri içerisinde yer alan göstergebilimsel analiz yöntemi kullanılarak incelenmiştir. Çalışma için seçilen posterler Fransız antropolog Claude Lévi-Strauss'un İkili Karşıtlıklar Modeli üzerinden ele alınmıştır. Çalışmada özellikle LéviStrauss'un "somutlama mantığı" üzerinden analizler yapılmıştır. Elde edilen bulgularda Çin propaganda posterlerinde ABD'nin işgalci, barbar, katil soyut kavramları üzerinden somutlanarak, Çin kamuoyunda ABD karşıtı nefret söylemi inşa edilmeye çalışıldığı ortaya konulmuştur..

Anabtar Kelimeler: Kore Savaşı, Çin, ABD, Propaganda, Uluslararası İlişkiler

\section{The Analysis of USA-China Relations on Chinese Propaganda Posters in the Context of Korean War}

\begin{abstract}
The People's Republic of China intervened in the Korean War on 25 October 1950 and sent military aid to North Korea. With the help of China, the fate of the war changed and the USA lost its initiative in the war. In this process, the Chinese government started propaganda campaign against the USA to get support from the Chinese people. China effectively used the posters as a propaganda tool and tried to mobilize the Chinese people against the USA. Within the scope of the study, it was tried to reveal how posters were used for anti-USA discourses by Chinese propaganda in the Korean War. For the purpose, six propaganda posters were selected by using the method of sampling from International Institute of Social History (IISH). The posters selected for the study were discussed by the French Anthropologist Claude Lévi-Strauss's Binary Contrast Model. In the study, especially the analysis was made via the embodiment of logical of Lévi-Strauss. The findings of the study revealed that the Chinese propaganda posters were based on US occupation, barbaric, and killer abstract concepts.
\end{abstract}

Key Words: Korean War, China, USA, Propaganda, International Relations

Atıf İçin / Please Cite As:

Karaca, M., Gazi, M. A. ve Çakı, C. (2020). Kore savaşı ekseninde ABD-Çin ilişkilerinin Çin propaganda posterleri üzerinden analizi. Manas Sosyal Araştırmalar Dergisi, 9(2), 1142-1156.

Geliş Tarihi / Received Date: 12.04.2019

Kabul Tarihi / Accepted Date: 03.06.2019

\footnotetext{
${ }^{1}$ Doç. Dr. - Anadolu Üniversitesi İktisadi ve İdari Bilimler Fakültesi, mustafa_karaca@anadolu.edu.tr ORCID: 0000-0002-8204-6154

${ }^{2}$ Dr. Öğr. Üyesi - Malatya Turgut Özal Üniversitesi Battalgazi MYO, mehmetaligazi@hotmail.com ORCID: 0000-0002-9239-4187

3 Araş. Gör. - İnönü Üniversitesi İletişim Fakültesi, caner.caki@inonu.edu.tr ORCID: 0000-0002-1523-4649
} 


\section{Giriş}

25 Haziran 1950 tarihinde Kore Savaşı, Kuzey Kore ve Güney Kore arasında meydana gelen bölgesel bir çatışma olarak başlamıştı. Buna karşın ilerleyen süreçte Kuzey Kore'ye karşı ABD ve müttefiklerinin müdahalesiyle savaş uluslararası bir boyut kazanmıştı. ABD'nin liderlik ettiği koalisyon güçleri, Kuzey Kore'de üstünlük elde etmiş ve zaman içerisinde Çin sınırına kadar yaklaşmıştı. Bunun üzerine Çin Halk Cumhuriyeti, 25 Ekim 1950 tarihinde savaşa dâhil olarak Kuzey Kore'ye yüz binlerce asker göndermişti. Çin'in savaşa müdahalesi, savaşın dengesinin değişmesine ve koalisyon kuvvetlerinin geri çekilmesine yol açmıştı. İlerleyen aşamada her iki taraf da birbirlerine karşı üstünlük sağlayamamıştı. Bu süreçte Çin, ABD karşıtı yoğun bir propaganda faaliyetine girişerek, Çin halkının savaştaki desteğinin sürmesine çalışmıştır. Çin propagandasının bu aşamada en sık kullandığı kitle iletişim araçlarından biri posterler olmuştur. Çalışma kapsamında Kore Savaşı sırasında ABD karşıtı kamuoyu oluşturmada Çin propaganda posterlerinin nasıl ve ne yönde kullanıldıkları göstergebilimsel analiz yardımıyla incelenmiştir.

Ulusal çalışmalar içerisinde son dönemde propaganda disiplini üzerine göstergebilimsel analiz metodu kullanılarak farklı dönem ve ülkeler ile ilgili akademik çalısmaların yapıldığı görülmektedir. Bu çalsşmalar içerisinde; Çak1 (2018a), "İkinci Dünya Savaşı'ndaki Propaganda Savaşlarında Çizgi Filmin Rolü: Nazi Almanyası ve Amerika Birleşik Devletleri Üzerine İnceleme" adlı çalısmada İkinci Dünya Savaşı'nda çizgi filmlerin propaganda amaçlı kullanımını Lévi-Strauss'un İkili Karşıtlıklar Modeli üzerinden ABD ve Nazi Almanyası özelinde analiz etmiștir. Çalışma sonucunda elde edilen bulgularda her iki ülkenin de hazırlanan propaganda içerikli çizgi filmlerde birbirlerine karşı nefret söylemi inşa etmeye çalıştıkları ortaya çıkmıştır. Yine Çak1 (2018b), "Adolf Hitler'in Kült Lider İnşasında Kullanılan Propaganda Posterlerinin Göstergebilimsel Analizi" adlı çalışmada Nazi Almanyası lideri Adolf Hitler'in propaganda posterleri üzerinden kült lider olarak nasıl inşa edildiğini Fransız dilbilimci Roland Barthes göstergebilimsel analiz metodu kullanarak incelemiştir. Çalışmada posterler üzerinden Hitler'in Almanya'yı yönetecek en doğru kişi olduğu propaganda mitinin inşa edilmeye çalışıldığı, bu yolla kitlelerin Hitler'in otoritesini doğrudan kabul etmesinin amaçlandığı ortaya çıkarılmıştır. Gazi, Çakı ve Gülada. (2018a), "İkinci Dünya Savaşı'nda Sovyet Kült Lider Propagandasında Vladimir Lenin ve Joseph Stalin'in Sunumu" adlı çalışmada Sovyetler Birliği lideri Joseph Stalin'in kült liderlik propagandasında posterlerin kullanımını ABD'li dilbilimci Charles Sanders Peirce'in göstergebilim modeli üzerinden analiz etmiştir. Çalışmada sonucunda Stalin'in posterlerde doğrudan Vladimir Lenin'in kült liderliğinden yararlanılarak Sovyetler Birliği'nin yeni kült lideri olarak sunulduğu ortaya konulmuştur. Gazi, Çak1 ve Gülada (2018b), "İspanya 2000 Partisi'nin Göçmen Karşıtı Propaganda Faaliyetleri Üzerine İnceleme" adlı çalışmada İspanya'daki İspanya 2000 Partisi'nin (España 2000, E-2000) göçmen karşıtı propaganda faaliyetlerini İsviçreli dilbilimci Ferdinand de Saussure'ün Göstergeler Modeli üzerinden ele almıştır. Çalışmada elde edilen bulgularda E-2000'nin göçmen sorununu istatistiki veriler sunarak İspanya kamuoyunda ön plana çıkarmaya çalıştığı buna karşı propagandasında göçmen soruna yönelik net vaatlere yer vermediği ortaya çıkarılmıştır.

"Soğuk Savaş dönenimin ilk sıcak çatışması olarak kabul edilen Kore Savaşı'nda, Çin propaganda posterlerinde Çin-ABD ilişkileri nasıl sunulmaktadır?" şeklindeki soru çalışmanın temel problemini oluşturmaktadır. Elde edilen bulgular kapsamında Kore Savaşı'nın iki ülkenin ilişkilerine ne şekilde yansıdığı ortaya konulmaya çalışılmışıı.

\section{Kore Savaşı ve Çin Halk Cumhuriyeti}

İkinci Dünya Savaşı'nın sonlanmasından sonra ABD ve Sovyetler Birliği, dünyanın iki süper gücü olarak uluslararası siyasette etkili olmaya başlamışı. Buna karşın zaman içerisinde her iki ülke, Mihver Devletleri'nden geri alınan bölgelerde kurulacak yönetimler konusunda anlaşmazlığa düşmüştü. $\mathrm{Bu}$ ülkelerin başında da Kore gelmişti. Kore yarımadası stratejik önemi nedeniyle 20. yüzyıllın başından itibaren pek çok ülkenin dikkatini çeken bir bölge olmuştu. Yarımada, 1905 yllında gerçekleştirilen JaponRus Savaşı'ndan sonra Japon İmparatorluğu'nun denetimine girmişti (Nish, 2014, s. 2). Japonya, 1945 yllında Müttefik Devletleri'ne teslim olarak İkinci Dünya Savaşı'ndan ayrıllmış ve denetimi altında bulunan pek çok yerden olduğu gibi Kore'den de çekilmişti. Japonya'nın Kore'den çekilmesiyle birlikte bölgenin denetimi kısa bir süreliğine Müttefik Devletleri'nin eline geçmişti. Sovyetler Birliği, Kore'de komünizm ideolojisinin kurulmasını desteklerken, ABD buna şiddetle karşı çıkmıştı. Çünkü ABD, komünizm ideolojisi altında olacak bir Kore devletinin uluslararası arenada kendisi ile işbirliği içerisine girmeyeceğinden, hatta kendisine karşı oluşturulacak olan bir koalisyonda önemli bir rol üstlenebileceğinden çekinmekteydi. Bu amaçla Kore'de kendisini destekleyecek bir yönetimin iş başına 
gelmesi için çalışmaktaydı. ABD ve Sovyetler Birliği arasında uzlaşmanın sağlanamaması üzerine Kore'nin kuzey ve güney olmak üzere ikiye bölünmesine, kuzeyde Sovyet yanlısı, güneyde ise ABD yanlısı bir hükümetin kurulmasına karar verilmiști. Kurulacak iki ülkenin sınırları da 38. enlem olarak belirlenmiști (Lowe, 2014, s. 20). Sovyetler Birliği ve ABD'nin kendi destekledikleri hükümetler, Kore'de iş başına gelince kuvvetlerini geri çekmişti. Buna karşın Kuzey Kore, Güney Kore üzerindeki emellerinden vazgeçmemişti. Her iki ülkenin de komünizm ideolojisi altında yönetilmesini istemişti. Nihayetinde 25 Haziran 1950 tarihinde Kuzey Kore ordusunun 38. enlemi geçerek Güney Kore'yi işgale başlaması ile Soğuk Savaş dönemindeki ilk büyük çatışma da başlamış oldu. Birleşmiş Milletler Güvenlik Konseyi, Kuzey Kore'nin saldırısına karşı ortak bir askeri harekat düzenleme kararı almıştı (Gilbert, 2011, s. 1037). Bu harekatta özellikle ABD öncü bir rol üstlenmişti. Nitekim ABD, Kuzey Kore ordusunun Güney Kore'yi işgal etmesi halinde önemli bir müttefikini kaybedeceğinde endişen etmişti. Bunun yanında komünistlerin Güney Kore'de elde edecekleri zaferin bölge ülkeleri için bir domino etkisi oluşturacağından ve diğer Asya ülkelerinde de komünist yönetimlerin kurulacağından çekinilmişti.

ABD'nin öncülüğünde hazırlanan BM kuvvetleri, aynı yıl Kuzey Kore Birlikleri'ne karşı saldırıya geçmişti. BM kuvvetleri, Kuzey Kore ordusunu Güney Kore'den geri püskürtmeyi başarmıştı. İlerleyen süreçte BM kuvvetlerinin başarılı harekatları devam etmiş ve BM kuvvetleri Çin sınırına kadar yaklaşmışı (Mcmahon, 2013, s. 72-73). Kuzey Kore ordusu teknik ekipman bakımından gelişmişs silahlara sahip BM ordusu karşısında önemli bir varlık gösterememeye başlamıştı. Bu süreçte Kuzey Kore'ye açıktan destek veren Çin yönetimi, BM kuvvetlerinin ilerlemesi karşısında doğrudan savaşa dahil olma kararı almıştı. Böylece yarımadada ABD ordusu hem Kuzey Kore hem de Çin kuvvetleri ile karşı karşıya kalmışı (Cumings, 2010, s. 25). Buna karşın Çin ve ABD, karşılıklı olarak savaş ilanında bulunmamış, Kuzey ve Güney Kore üzerinden çatışmalarda yer almayı seçmişti.

Kore Savaşı başladığında Çin, iç savaştan yeni çıkmış ve ülkede Mao Zedong liderliğinde komünist bir rejim kurulmuştu. Ülkenin ismi de Çin Halk Cumhuriyeti (ÇHC) olarak değiştirilmişti. Mao, Çin'de tamamen kült lider olarak inşa edilmişti (Landsberger, 1996, s. 196). Bu açıdan Çin, doğrudan Mao'nun öğretileri içerisinde yönetilmekteydi. Hatta Mao öldükten sonra bile ülkedeki etkisi devam etmişti (Barmé, 2016, s. 14). Mao'nun denetiminde ülkede iç karışıklıklara son verilmişti. Sovyetler Birliği gibi ÇHC, doğrudan Batılı ülkelere karşı cephe alarak, bölgede komünist rejimlerin kurulmasına önderlik etmeye başlamıştı. Komünist bir rejimin kurulmasını desteklediği ülkelerin başında da Kore gelmekteydi. Nitekim Kore yarımadası, Çin'in Kuzey Doğu sınırlarının savunulmasında hayati derece önem taşıyan bir konumdaydı. Bu süreçte Çin, Kore'de Çin karşıtı kurulabilecek bir yönetimin, kendisi için büyük bir tehdit oluşturabileceğini planlamaktaydı. Çin bu nedenle BM kuvvetlerinin sınırlarına yaklaşmasından dolayı Kore'ye asker göndermeyi kararlaştırmıştı (Kissinger, 2010, s. 468). Çin yönetimi, doğu sınırında ABD ordusunun konuşlanmasından çekinmekteydi. $\mathrm{ABD}$, komünist rejime karşı tehlike olarak değerlendirilmekteydi. Çin'in müdahalesi, savaşın Kuzey Kore lehine değişmesine yol açmıştı. Çin kuvvetleri, BM kuvvetlerini Çin-Kore sınırında durdurmuş ve 38.enlemin güneyine kadar geri çekilmesini sağlamıştı. İlerleyen süreçte her iki taraf da birbirine karşı üstünlük sağlayamamış ve çatışmalar yıpratma savaşına dönüşmüştü. Buna karşın taraflar arasında ateşkes sağlanamamıştı (Xia, 2014, s. 65). Diğer yandan savaşta ABD kuvvetleri, Kuzey Kore'yi yoğun bir şekilde bombalamış ve ülkenin ağır kayıplara uğramasına neden olmuştu. ABD tarafından gerçekleştirilen bombardımanlar, Çin yönetiminin ABD'ye karşı direnişi şiddetlendirmekteydi.

Kore Savaşı'na müdahalesine karşılık olarak ABD tarafindan, Çin endüstrisinin hava kuvvetleri ile bombalanması ve ABD donanmasının Çin'in kıyı kesimlerine saldırı düzenlemesi söz konusu haline gelmişti (Stueck, 1997, s. 149). ABD'nin Çin'in yanında müdahalede bulunması gereken bir diğer ülke de Sovyetler Birliği olmuştu. Nitekim Çin, savaş döneminde Sovyetler Birliği ile ilişkilerini geliştirmiş ve ikili arasında sıkı dostluğa dayalı güçlü bir ittifak meydana gelmişti (Lewis ve Xue, 1993, s. 266). ABD bu süreçte her iki ülkenin anakarasına doğrudan müdahale etmektense, Kuzey Kore'de savaşan kuvvetler üzerinde üstünlük kurmayı tercih etmişti. Böylece Kore Savaşı'nın bir dünya savaşına dönüşmesini engellemişti. Kore Savaşı, 27 Temmuz 1953 tarihinde imzalanan ateşkes antlaşmasıyla son bulmuştu. Savaşta sınırlarda ciddi bir değişiklik yaşanmamış, buna karşın savaşan her iki tarafta da ağır kayıplar meydana gelmişti (Gaddins, 2018, s. 60). Kore Savaşı, komünizm ideolojisi altında yönetilen Çin'in ilk geniş çaplı uluslararası müdahalesi olmuştu. Diğer yandan Çin, Sovyetler Birliği'nin komünizm ideolojisinin savunulmasındaki ve yayılmasındaki liderliğine karşı önemli bir rakip olduğunu da Kore Savaşı ile birlikte göstermişti. 


\section{Kore Savaş1'nda Çin Halk Cumhuriyeti'nin Propaganda Faaliyetleri}

Propaganda, bir grubun görüş ve düşüncelerini değiştirmek ve grubu kontrol altında tutmak amaciyla ortaya konulan her türlü bilgi, belge ve görüşü ifade etmektedir (Tarhan, 2010, s. 36). Propagandanın tarihi insanlık tarihi kadar eski olmakla birlikte, en yaygın kullanıldığı dönem, 20. yüzyıl olmuștu. Bu yüzyılda dünya tarihindeki en büyük propaganda savaşları yaşanmışıtı. Bu dönemde gazete, dergi, radyo, sinema, televizyon gibi pek çok kitle iletişim aracı propaganda amaçlı etkin bir şekilde kullanılmıştır (Çakı, 2018c, s. 1569). Nazizm, Faşizm, Komünizm gibi farklı ideolojilerin ortaya çıktığ1 bu yüzyılda, kitlelerin düşüncelerini kontrol altında tutabilmek için propagandadan yoğun bir şekilde yararlanılmıştır. Bu süreçte propaganda disiplininden en fazla yararlanan ülkelerin başında ÇHC gelmektedir.

ÇHC'nin kurulmasından sonra da ülke genelinde yoğun bir şekilde sosyalizmin etkisi görülmeye başlanmıştı (Priestland, 2017, s. 325). Bu aşamada Çin'de komünizm ideolojisinin hâkim olmasında ve Mao'nun ülke genelinde otorite kurmasında propaganda önemli bir rol oynamıştır (Domenach, 2003, s. 16; Leese, 2011, s. 38). Çin propagandası yeni rejime karşı kitlelerin desteğini alabilmek farklı yöntemlerden yararlanmıştı. Bu süreçte Çin propagandası kendine has bir özellik kazanmıştı. Çin propagandasının en önemli özelliklerinden biri onlarca farklı dilde faaliyet gösterebilmesi olmuştu. Nitekim Çin'in pek çok farklı etnik kimlikten oluşması Çin propagandasını da zorunlu olarak farklı dillerde yayın yapmaya zorlamıştı. Özellikle ÇHC'nin ilk dönemlerinden itibaren radyo propaganda amaçlı yoğun bir şekilde kullanılmıştı (Jowett ve O'donnell, 2014, s. 133). Yine posterler de önemli bir propaganda arac1 olarak hizmet etmiştir. Özellikle ÇHC'nin kurulduğu ilk yıllarda okuma-yazma oranının düşük olduğu hesaba katıldığında, her iki kitle iletişim aracının da propaganda boyutunda ne kadar önemli bir görev üstlenebileceği anlaşılabilmektedir.

Çin İç Savaşı'ndan sonra ÇHC propagandasında yoğun bir şekilde ABD karşıtlığının ön plana çıktığı görülmüştür. Bunun altında iki temel yatmaktadır. Birincisi ABD'nin Çin Komünist Partisi'ne (ÇKP) karş1 Çin Milliyetçi Partisi (Kuomintang) lideri Çan Kay Şek'e, vermiş olduğu destektir (Lawrance, 2013, s. 3). $\mathrm{ABD}$, böylece ÇKP'nin en büyük rakibine destek vererek, kendisini doğrudan ÇHC'nin karşına almaktaydı. İkinci neden ise tamamen ideolojik merkezli olmaktaydı. Çin, ABD'yi emperyalist bir ülke olarak değerlendirmekteydi (Yufan ve Zhihai, 1990, s. 94). Bu nedenle ÇHC'nin komünizm ideolojisinin savunuculuğunu yapması, doğrudan ABD'nin kapitalist söylemlerine karşı hareket etmesine yol açmaktaydı. Bu süreç de her iki ülkeyi karşı karşıya getirmekteydi.

Kore Savaşı başladığında, ÇHC'de bulunan Amerikan karşıtlığı daha belirgin bir şekilde gün yüzüne çıkmaya başlamıştı. ABD, Çin propagandası tarafindan komünizm ideolojisine karşı en büyük tehdit olarak sunulmaktaydı. Bu süreçte ABD'ye karşı Çin hükümeti hem halkının hem de ordusunun savaşa müdahale etmesi için yoğun bir çaba sarf etmişti. ABD, Kuzey Kore ve Çin'e karşı uluslararası bir propaganda faaliyeti yürütmüştü (Stueck, 2013, s. 153). Buna karşı Çin'in teknolojik bakımından sınırlı imkanları ve uluslararası alanda etkin bir konumda olamaması, propaganda faaliyetlerinin yerel bir düzeyde kalmasina yol açmıştı. Çin propagandası, savaşta kahramanlık gösteren askerler üzerinden de kitleleri etkilemeyi amaçlamıştı. Bunlardan biri de Yang Gensi adlı askerin yaşamının anlatımı olmuştu. Gensi'nin Müttefik Devletleri'ne karşı mücadelesi, kahramanlık hikayesi olarak sunulmuştu (Sandler, 2015, s. 226). Kore Savaşı'nda Çin'in ABD'nin Asya'daki varlığına karşı çıkması, Çin'in yükselişinin önünü açmıştı ve ülkeyi bölgesel bir dünya gücü haline getirmişti. Diğer yandan Kore Savaşı'nda Çin hükümeti tarafindan yürütülen $A B D$ karşıtı propaganda, savaşın ÇKP'nin iç desteğini ve meşruiyetini güçlendirmiş, Çin halkının partinin düşünceleri etrafinda harekete geçmesini sağlamış ve partinin otoritesini Çin genelinde pekiştirmesine yol açmışı (Rawnsley, 2009, s. 285). Çin propagandası bu aşamada ABD karşıtllı̆ı oluşturabilmek için pek çok yolu denemişti. Örneğin Çin'de propaganda amaçlı ABD karşııtı şarkılar yapılmıştı. Diğer yandan ABD ordusunu eleştiren karikatürler hazırlanmıştı. Hazırlanan propaganda karikatürleri ile Amerikalar çirkin ve sarhoş şekillerde yansıtılmaya başlanmıştı (Cathcart, 2010, s. 205). Çin propagandası bu şekilde Çin halkı nezdinde güçlü bir ABD karşıtllğı meydana getirmeye ve kitleleri ABD ordusuna karşı harekete geçirmeye çağırmıştı.

Çin propagandası, bir yandan ülke genelinde ABD karşıtlığı meydana getirirken, diğer yandan da Çin ve Kore ilişskilerinin gelişmesi yönünde de önemli adımlar atmaktaydı. Nitekim 1950'li yılların ilk yarısındaki propaganda kampanyalarında Çinlilerin Korelilere sempati duyduğu aktarılmaktaydı. Diğer yandan Çin propagandası yabancı tehditleri de kitleleri seferber etmek için kullanmaktaydı (Chen, 2010, s. 13). ABD'nin Çin'e veya komünizm ideolojisine yönelik herhangi bir olumsuz söylemi, Çin propagandası 
tarafindan ABD'nin tehditkâr bir düşman olarak algılanmasına yol açmaktaydı. Benzer şekilde kitlelerin gelecekte ABD tarafından gelebilecek muhtemel bir saldırıya karşı da hazır olmasını sağlamaktaydı.

Çin propagandası tarafindan yürütülen propaganda faaliyetlerinde ABD'ye, Çin'e yönelik herhangi bir tehdidin güçle karşılanabileceği mesajını da vermeye çalışmaktaydı (Rawnsley, 2009, s. 285). Çin propagandasının tüm amacı, Çin ordularının Kore Savaşı'na dahil olmasına meşru bir zemin hazırlamak ve Çin savaşa dahil olduktan sonra da Çin ordularının ABD'ye karşı kararı bir şekilde savaşmasını sağlamaktı.

Kore Savaşı sonlandıktan sonra da iki ülke arasındaki olumsuz ilişkilerin soğuması oldukça uzun bir zaman almıştı. Bu süreçte her iki taraf da propaganda faaliyetlerini sinema üzerinden yürütmeye başlamıştı. Sinema üzerinden yürütülen propaganda savaşlarının amacı Kore Savaşı sona erdikten hemen sonra siyasi mesajlar iletmek ve kitlelere uzun vadeli dersler vermek olmuştu (Pickowicz, 2010, s. 352).

\section{Yöntem}

Kore Savaşı'nda Çin propagandası tarafindan kullanılan posterler üzerinden Çin-ABD ilişkilerinin ortaya çıkarılması çalışmanın temel amacını oluşturmaktadır. Ulusal alandaki akademik çalışmalarda yapılan kapsamlı literatür taraması sonucunda Çin Halk Cumhuriyeti'nin propaganda faaliyetleri üzerine herhangi bir akademik çalışmaya rastlanılamamıştır. Bu açıdan mevcut çalışma ile alanda önemli bir boşluğun doldurulması amaçlanmaktadır. Diğer yandan çalışma, Kore Savaşı'nda Çin-ABD ilişkileri ile ilgili bilgi vermesi ve propagandanın uluslararası ilişkilerdeki rolünü ortaya koyması nedeniyle önem taşımaktadır.

Kore Savaşı'nda Çin propagandası tarafindan hazırlanan tüm propaganda posterlerinin incelenmesinin güçlügünden dolayı çalışmada örneklem kullanılması yoluna gidilmiştir. Bu amaçla çalışmada amaçlı örneklem metodu kullanılarak belirlenen altı propaganda posteri üzerinden incelemede bulunulmuştur. Çalışmada analiz edilen Çin propaganda posterleri, Uluslararası Sosyal Tarih Enstitüsü'nden (IISH) seçilmiştir (IISH, 2019). Çalışma kapsamında Çin yönetimi tarafından ABD karşıtı çok sayıda propaganda posterinin kullanıldığı gözlemlenmiştir. Kullanılan posterlerin konu ve içerik bakımından birbirlerine benzer nitelikte olduğu saptanmış ve posterler altı başlık altında sınıflandırılmıştır. Sınıflandırılan konu başlıklarından amaçlı örneklem metodu kullanılarak konuyu en iyi şekilde yansıtılacağı düşünülen altı propaganda posteri çalışmanın örneklemi olarak belirlenmiştir. Çalışmada yalnızca alıı Çin propaganda posteri üzerinden incelenmesi ve elde edilen bulgular kapsamında genellemelerde bulunulması çalışmanın temel sinırlılığını oluşturmaktadır.

Alanda yapılan kapsamlı literatür taramasında, genel olarak Çin Kültür Devrimi'nde kullanılan propaganda posterlerinin incelendiği ortaya çıkmıştır (Cushing ve Tompkins, 2007; Powell ve Wong, 1997; Xing-Hua, 2005; Yang ve Suchan, 2009; Shen, 2000). Nitekim bu dönemde propaganda posterlerinin yoğun olarak kullanılması araştırmaların da yoğunluğunu arttırmışır. Buna karşın ÇHC'nin kurulduğu ilk yıllara denk gelen Kore Savaşı sırasında kullanılan propaganda posterlerinin incelendiği herhangi bir akademik çalıssmaya rastlanılamamıştır. Çalışmada ÇHC'nin propaganda faaliyetlerinin emekleme dönemi olarak kabul edilen kuruluş döneminde, Kore Savaşı sırasındaki Çin-ABD ilişkilerinin propaganda posterlerindeki sunumu analiz edilmeye çalışılmıştır. Literatüre bağlı olarak çalışmada, Çin propaganda posterlerinde ABD'nin olumsuz bir anlatım ile sunulması, savaşın Çin ve Kuzey Kore orduları tarafindan kazanılacağının vurgulanılması ve komünizm ideolojisinin yüceltilmesi sonuçlarına ulaşılması beklenilmiştir.

"Soğuk Savaş dönenimin ilk sıcak çatışması olarak kabul edilen Kore Savaşı'nda, Çin propaganda posterlerinde Çin-ABD ilişkileri nasıl sunulmaktadır?" çalışmanın temel sorunsalı olarak belirlenmiş ve çalışma kapsamında aşağıdaki sorulara yanıt aranması amaçlanmıştır;

Kore Savaşı sırasında Çin propagandası tarafindan kullanılan posterlerde;

- Verilmek istenen temel propaganda mesajları nedir?

- $\mathrm{ABD}$ hangi olumsuz kavramlar üzerinden sunulmaktadır?

- ABD karşıtı hangi propaganda mitleri inşa edilmeye çalışılmaktadır?

- Çin yönetimi, uluslararası mı yok yerel bazda mı posterleri propaganda amaçlı kullanmaktadır?

Çalışmada nitel araştırma yöntemleri içerisinde yer alan göstergebilimsel analiz metodu kullanılmıştır. Çalışma kapsamında belirlenen propaganda posterleri Fransız antropolog Claude Lévi-Strauss'un İkili Karşıtlıklar Modeli üzerinden analiz edilmiştir. Özellikle propaganda posterlerinde "somutlama mantı̆̆ı" üzerinden ABD'nin hangi soyut kavramlar üzerinden sunulduğu ortaya konulmaya çalışılmıştır. 
Göstergebilim, göstergeler üzerinden inşa edilen anlamları inceleyen bir bilim dalıdır (Guiraud, 2016, s. 17). 20. yüzyılın başlarında dilbilimi alanında yapılan çalışmalar ile ortaya çıkan ve zamanla bir bilim dalı haline gelen göstergebilimin ilk temsilcileri, İsviçreli dilbilimci Ferdinand de Saussure ve ABD'li dilbilimci Charles Sanders Peirce'dir (Sı̆̆ırc1, 2016, s. 30). Her iki dilbilimci de yapmış olduğu çalışmalar ile göstergebilimin temelini atmış, buna karşın göstergebilim sosyal bilimler alanında yaygın bir araştırma metodu haline gelmesi için belirli bir zamanın geçmesi gerekmiştir. Saussure ve Peirceden sonra göstergebilim alanında çalışmalar yürüten pek çok felsefeci ortaya çıkmış ve ortaya koydukları göstergebilim modelleri ile disiplinin gelişmesine katkı sağlamıştır. Bu felsefeciler içerisinde yer alan Fransız antropolog Claude Lévi-Strauss, yapmış olduğu araştırmalar ile göstergebilime önemli katkılar sağlamıştır. Özellikle bunların başında da göstergebilim alanında ortaya koyduğu "İkili Karşıtlıklar Modeli" gelmektedir.

Lévi-Strauss, toplumlar arasında ortaya çıkan ayrışmanın kültürler arasındaki farklılaşma eğiliminden kaynaklandığ1 savunmuştur. Lévi-Strauss, eşyaların insan eliyle oluşturulduğu için kişiden kişiye farklılaşabileceğini aktarmaktadır (Lévi-Strauss, 2012, s. 22). Bu açıdan kültürlerin kullandığı göstergelerin de farklılaşabildiği söylenebilmektedir. Bir kültürün kendi değerlerini üstün görmesi neticesinde diğer kültürleri "yaban" olarak nitelendirebileceğini savunmuştur (Fiske, 2017, s. 222). Bu amaçla 1930'lu yıllarda Brezilya'da "ilkel" olarak adlandırılan yerel kabileler üzerine yapmış olduğu incelemelerde, "ilkel" veya "yaban" olarak adlandırılan kültürlerin aslında ilkel olmadığı sonucuna ulaşmıştır (Lévi-Strauss, 2018a, s. 28). Yerel kabilelere atfedilen "yaban" kelimesinin, yerel kabilelerin Batılı toplumlar gibi yaşamamasından, onların geliştirdiği araçları kullanmamasından ve onların değerlerini benimsememesinden kaynaklandığını savunmuştur (Lévi-Strauss, 2014, s. 87). Buna karşın Lévi-Strauss, aslında "yaban" olarak adlandırılan toplumların pek çok konuda kendisini geliştirdiğini ileri sürmüş, yaban olarak adlandırılmalarının temelinde ise farklı kültürler tarafindan atfedilen soyut kavramlar olduğunu açıklamıştır. Lévi-Strauss, bir kültürün kendisini olumlu, kendisini dışındaki kültürleri de olumsuz soyut kavramlar üzerinden somutladığını belirtmiştir. Kültürler arasında birbirleriyle zıt soyut kavramlar üzerinden yapılan somutlamalara da İkili Karşıtlık Modeli adını vermiştir. Bu șekilde iki öğe bütünü üzerinden karşıtlıkların ortaya konulması amaçlanmıştı (Rifat, 2013, s. 120). Lévi-Strauss, model kapsamında bir kültürün kendi değerlerini en doğru kurallar bütünü olarak savunduğunu belirtmiştir (Lévi-Strauss, 2017, s. 70). Diğer yandan kültürün kendisi gibi olmayanları da kimi zaman tehlikeli bir düşman olarak yansıttığını savunmuştur.

Çalışma kapsamında Çin propaganda posterlerinde hangi somutlamalar üzerinden Çin ve ABD ordularının sunulduğu ortaya konulmaya çalışılmış, bu şekilde Çin propagandası tarafindan ABD'nin nasıl düşman olarak kitlelere yansıtılmaya çalışıldığının ortaya konulması amaçlanmıştır.

\section{Analiz}

Çalışmanın bu bölümünde "Katliam", "İdam", "Zafer", "Kutlama", "Barış" ve "Emperyalizm" başlıklı propaganda posterleri göstergebilimsel açıdan incelenmiştir.

\section{"Katliam" Konulu Propaganda Posteri}

Çin propagandası tarafindan Amerika, savaştan nefret etmenin ana konusu haline getirilmişti. Kore Savaşı, ÇHC'de “Amerika'ya Direniş ve Kore'ye Yardım Etme Savaşı” olarak sunulmuştu. Amerika'ya karşı nefret kampanyasında, ABD askerleri Kore'de kana susamış katiller ve ahlaksızlar olarak lanetlenmişti (Sandler, 2015, s. 226). 1950 tarihli "Katliam" konulu propaganda posterinin tasarımcis1 Xu Ling'dir. Posterde Koreli sivilleri bıçaklayan ABD askeri ve Kore şehirlerini bombalayan ABD Hava Kuvvetleri'ne ait bir uçak resmedilmektedir. Posterin arka alanında da alev görsellerine yer verilmektedir. Posterin altında "Çin halkı, kesinlikle başka ülkelerin işgaline mahkûm edilemez ve kendi komşularını hareket etmeden gizlice sokabileceğini düşünen herhangi bir emperyalisti dinleyemez" yazılı kod bulunmaktadır. 


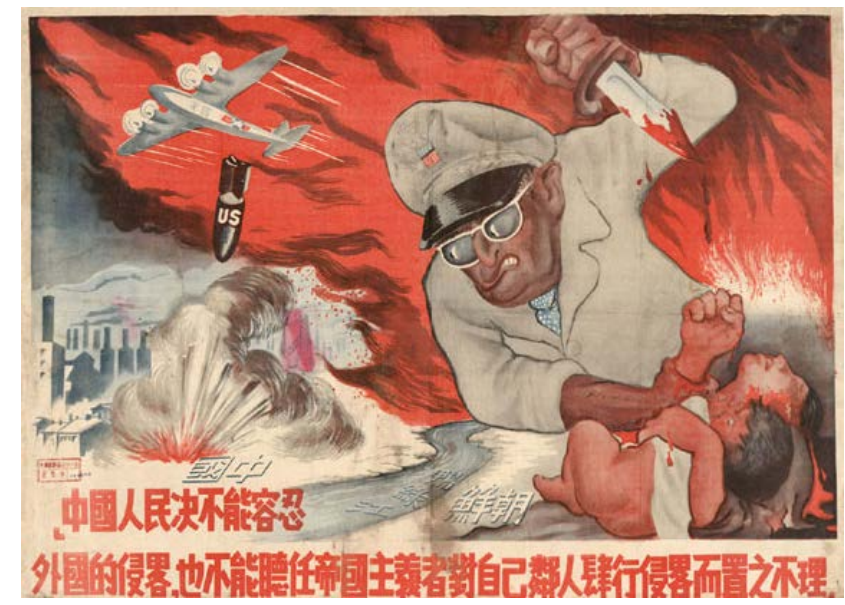

Resim 1. "Katliam" Konulu Propaganda Posteri

Posterde yer alan Amerikan askeri tüm Amerikan ordusunun, Koreli siviller de tüm Kore halkının metonimi (temsili) olarak ön plana çımaktadır. Böylece Çin propagandası mesajın genele verilmesini amaçlamaktadır. Posterde doğrudan "Amerikan ordusu Kore'de sivil halka katliam yapmaktadır" şeklinde propaganda miti inşa edilmeye çalışılmaktadır. Bu amaçla posterdeki görsel kodlar üzerinden ABD askerleri, ölüm, suç, saldır1; Koreli siviller yaşam, masumiyet, savunma soyut kavramları üzerinden somutlanmaktadır. Çin propagandası, ABD'nin Koreli sivilleri kurtarmak vaadiyle müdahalede bulunduğu Kore savaşında, söylediklerinin tam tersini yaparak sözde sivilleri katlettiğini aktarmaktadır. Diğer yandan ABD Hava Kuvvetleri tarafindan Kore üzerinde yapılan bombardımanlarda yalnızca sivil yerleşimlere zarar verildiği algısı oluşturulmaya çalışılmıştır. Yazılı kodlar üzerinden de Çin'in yaşanan sözde bu zulme kayıtsız kalamayacağı ve ABD'ye karşı müdahalede bulunacağı mesajı verilmektedir. Çin yönetimi, kendisini dünya kamuoyunda "kurtarıcı" olarak sunarken, ABD'yi de Koreli sivilleri ölüme sürükleyen "katiller" olarak yansıtmaktadır. Böylece Çin'in, Kore Savaşı'na yönelik müdahalesinde uluslararası alandan destek bulmaya çalıştı̆̆ı ortaya çıkmaktadır.

Tablo 1. "Katliam" Konulu Propaganda Posteri

\begin{tabular}{ccc}
\hline & Somut Kavramlar & \\
\hline ABD askerleri & Koreli siviller \\
\hline & Soyut Kavramlar & \\
\hline Ölüm & Yaşam \\
Suç & Masumiyet \\
Saldırı & Savunma \\
\hline
\end{tabular}

\section{"İdam" Konulu Propaganda Posteri}

1951 tarihli "İdam" konulu propaganda posterinin tasarımcısı Fang Ling'dir. Posterin çevresi büyük bir urganla çevrilmiştir. Posterin merkezinde ise Kore halkına zulmeden, katliam yapan ve şehirleri yağmalayan $\mathrm{ABD}$ askerleri resmedilmektedir. Posterin arka planında da Kore şehirlerini bombalayan ABD uçakları yansıtılmaktadır. Posterin üstünde "İki yana yaslanmış ilmek onları bekliyor!" yazılı kod bulunmaktadir. 


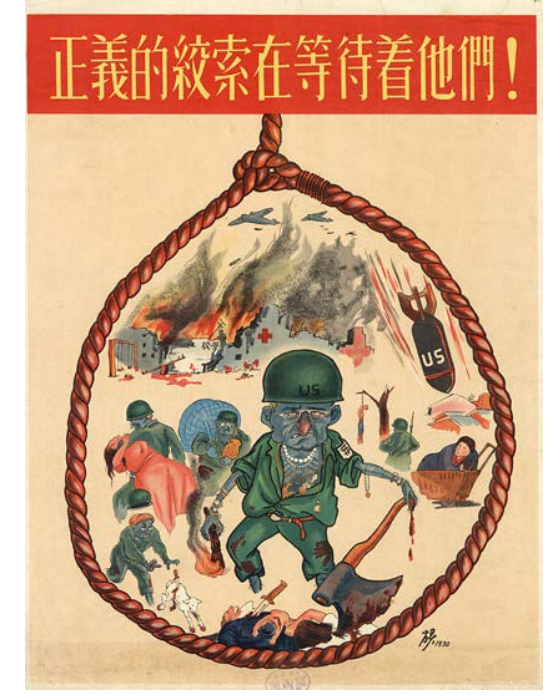

\section{Resim 2. "İdam" Konulu Propaganda Posteri}

Çin propagandası posterde resmedilen kişileri yine tüm ABD ordusu ve tüm Koreli sivillerin metonimi olarak aktarmaktadır. Posterdeki görsel kodlar üzerinden "ABD ordusu Koreli sivillere zulmediyor" şeklinde propaganda miti inşa edilmeye çalışlmaktadır. Posterde resmedilen ABD askerleri korkutucu olarak aktarlarak, kitleler nezdinde olumsuz bir imajla sunulmaktadır. Posterdeki görsel kodlarda ABD askerleri barbarlık, katliam, ölüm; Koreli siviller ise medeniyet, savunma ve yaşam soyut kavramları üzerinden somutlanmaktadır. Bu şekilde Çin propagandası, Kore halkının medeniyeti, ABD ordusunun da yıkım ve barlılığı temsil ettiğini vurgulamıştır. Yazılı kodlar üzerinden de yine ABD ordusunun bozguna uğrayacağı ve yaptıklarının bedelini ağır bir şekilde ödeyeceği aktarılmaktadır. Bu aşamada Çin propagandasının bir önceki posterde olduğu gibi doğrudan Kore Savaşı'na müdahalesini meşrulaştırmaya çalıştı̆̆ görülmektedir. Nitekim posterdeki görsel kodlar üzerinden ABD ordusunun büyük bir cezayı hak ettiği alg1sı oluşturulmak istenmekte ve bunun da Çin ordusunun müdahalesi ile olabileceği izlenimi verilmektedir.

Tablo 2. "İdam" Konulu Propaganda Posteri

\begin{tabular}{ccc}
\hline & Somut Kavramlar & \\
\hline ABD askerleri & Koreli siviller \\
\hline & Soyut Kavramlar & \\
\hline Barbarlık & & Medeniyet \\
Katliam & Savunma \\
Ölüm & Yaşam \\
\hline
\end{tabular}

\section{"Zafer" Konulu Propaganda Posteri}

1951 tarihli "Zafer" konulu propaganda posterinin tasarımcıları Zhang Ding, Dong Xiwen, Li Ruinian, Hua Tianyou, Li Keran, Li Kushan, Tian Shiguang, Huang Jun, Zou Peizhu, Wu Guanzhong'dır. Posterde bozguna uğramış olarak yansıtılan ABD askerleri resmedilmektedir. Posterin hemen arkasında da devasa büyüklükte iki Çin askerine yer verilmiştir. Çin askerleri ellerindeki silahlar ile ABD ordusuna saldırmaktadır. Görsel kodlar içerisinde askerlerden birisi sol eli ile ABD ordusunu işaret etmektedir. Posterin arka planında da kızıl bayraklar dalgalanmaktadır. Kore askerlerinin saldırıları üzerine ABD askerlerinin kaçmaya çalışı̆̆ı yansıtılmaktadır. Posterde "Yaşasın Kore Halk Ordusu ve Çin Halk Gönüllüleri Ordusu'nun zaferi!" yazılı kodu bulunmaktadır. 


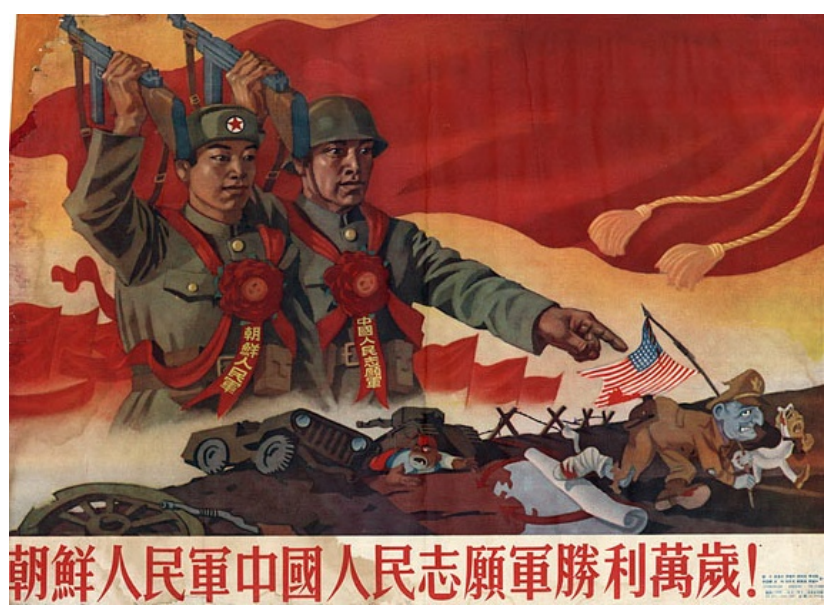

Resim 3. "Zafer" Konulu Propaganda Posteri

Posterdeki görsel kodlar üzerinden ABD'nin Kore'de büyük bir hezimete uğradığı aktarılmakta, ABD ordusunun geri çekilerek savaşı kaybettiği vurgusunun yapıldığı görülmektedir. Bu amaçla posterde kullanılan askerler sırasıyla Çin, Kuzey Kore ve ABD ordularının tümünün metonimi olarak kullanılmaktadır. Posterde Kore Savaşı'na yönelik Çin'in müdahalesi aktarılmaktadır. Çalışma kapsamında incelenen ilk iki posterde Çin propagandası, Çin ordusunun ABD'ye karşı Kore Savaşı'na müdahalesini meşrulaştırmak için çalıştı̆̆ görülmüştür. Bu posterde ise Çin'in doğrudan savaşa müdahil olduğu ve ABD ordusunu büyük bir hezimete uğrattığı mesaj1 verilmektedir. Posterde, "ABD, Kore Savaşı'nda komünist güçler tarafından yenilgiye uğratıldı" şeklinde propaganda miti inşa edilmeye çalışılmaktadır. Bu amaçla posterde ABD askerleri yenilgi ve saldırı; Çin ordusu ise zafer ve savunma soyut kavramları üzerinden somutlanmaktadır. Çin propagandası, ABD'nin yenildiği izlenimini oluşturarak Çinli ve Kuzey Koreli askerlerin daha istekli savaşmalarını hedeflenmektedir. Diğer yandan propaganda posterinde kızıl bayraklar üzerinden komünizm ideolojisinin de propagandası yansıtılmakta, Çin ve Kore halkı arasındaki ortak bağın komünizm olduğu vurgusu yapılmaktadır.

Tablo 3. "Zafer" Konulu Propaganda Posteri

\begin{tabular}{ccc}
\hline & Somut Kavramlar & \\
\hline Kore ordusu & & ABD ordusu \\
Kizil Bayrak & & \\
\hline & ABD bayrağ1 \\
\hline Yenilgi & & Zafer \\
Saldırı & & Savunma Kavramlar \\
\hline
\end{tabular}

\section{"Kutlama" Konulu Propaganda Posteri}

ÇHC'de tüm otorite Mao'nun elinde bulunmaktaydı. Mao üzerinden ülkede güçlü bir kült liderlik propagandası yürütülmekteydi (Paltiel, 1983, s. 49). 1951 tarihli "Kutlama" konulu propaganda posterinin tasarımcısı Zhang Biwu'dur. Posterde kutlama yapan Çin vatandaşları resmedilmektedir. Görsel kodlar içerisinde ellerinde kızıl bayrak ve Mao'nun resmi olan grubun bir yöne doğru hareket ettiği mesaj1 verilmektedir. Posterde "Amerika'ya karşı çıkmak, Kore'yi desteklemek, evi ve milleti korumak muhteşem" yazılı kodu bulunmaktadır. 


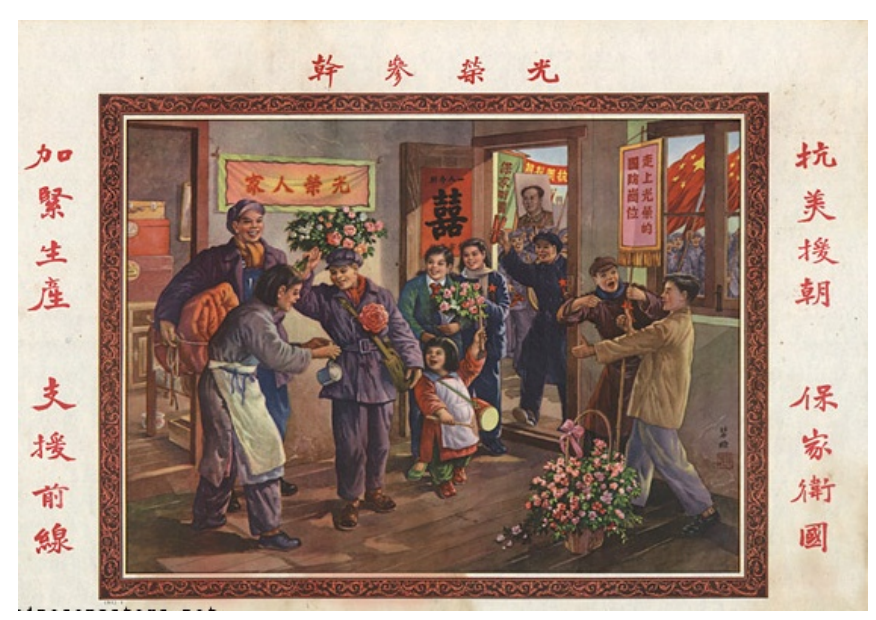

\section{Resim 4. "Kutlama" Konulu Propaganda Posteri}

Posterde Çin ordusunun Kore Savaşı sırasında ABD ordusuna karşı harekete geçtiği aktarılmaktadır. Posterdeki görsel kodlarda kızıl bayrakların taşınması komünizm ideolojisinin, Mao'nu resminin taşınması da Mao'nu kült liderliğinin Çin toplumu üzerindeki bir yansıması olarak sunulmaktadır. Halkın cepheye giden askerlere çiçekler vermesi ve kutlamalar yapması "Çin halkı Kore Savaşı'nda ABD'ye karşı müdahaleye destek vermektedir" propaganda mitinin inşa edilmesini sağlamaktadır. Posterdeki görsel kodlardan ABD'nin savaşı kaybedeceği, Çin ordusunun ise büyük bir zafer kazanacağı algısı oluşturulmaya çalışılmaktadır. Bu aşamada posterde Çin halkı sevinç ve zafer; ABD ordusu ise hüzün ve mağlubiyet soyut kavramları üzerinden somutlanmaktadır. Posterdeki yazılı kodlar da görsel kodları destekler mahiyette, Çin halkını ABD'ye karşı savaşa teşvik etmeye çalışmaktadır. Bu şekilde Çin yönetimi, Çin halkının Kore Savaşı'nda zorla savaştırıldığı algısını yıkmayı amaçlamakta ve Çin toplumunun genelinde savaşa yönelik büyük bir destek olduğu algısını inşa etmeyi hedeflemektedir.

Tablo 4. "Kutlama" Konulu Propaganda Posteri

\begin{tabular}{ccc}
\hline & Somut Kavramlar & \\
\hline Çin halkı & & ABD ordusu \\
\hline & Soyut Kavramlar & \\
\hline Sevinç & & Hüzün \\
Zafer & & Mağlubiyet \\
\hline
\end{tabular}

\section{"Barı̧̧" Konulu Propaganda Posteri}

1952 tarihli "Barış" konulu propaganda posterinin tasarımcısı bilinmemektedir. Posterde bombalanmakta olan bir köy resmedilmektedir. Posterin merkezinde ise çocuklarını bombalanan köyden kurtarmaya çalışan bir kadın yansıtılmaktadır. Sunum kodları içerisinde kadının sağ elini yumruk yaptığı ve öfkeli olduğu aktarılmaktadır. Posterde "Savaşın alevlerini ortadan kaldır, barışı koru!" yazılı kodu bulunmaktadir. 


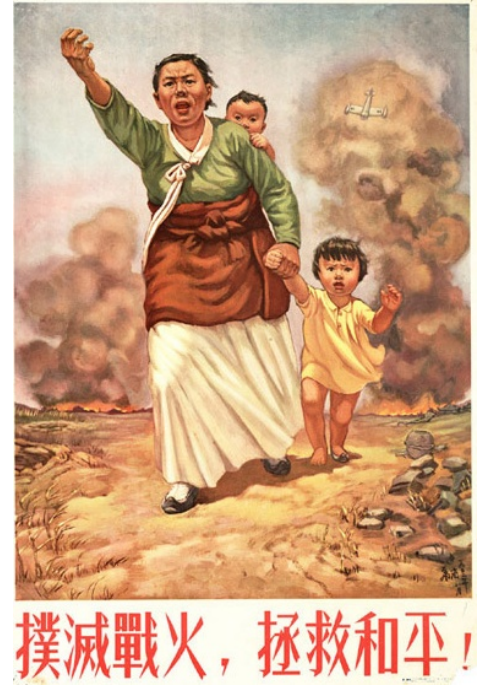

Resim 5. "Barsş" Konulu Propaganda Posteri

Propaganda posteri Kore Savaşıı'nın ikinci yılında hazırlanmışırı. Çin propagandası savaşın ikinci yllında da ABD ordusunun Koreli sivillere büyük ölçüde zarar verdiği algısını oluşturmaya çalıșmaktadır. $\mathrm{Bu}$ aşamada posterde resmedilen Koreli kadın ve çocukları, ABD ordusu tarafindan mağdur edilen Koreli sivillerin metonimi olarak yansıtılmaktadır. Kadının görsel kodlar içerisindeki jest ve mimikleri, ABD ordusuna karşı Koreli sivillerin öfkesinin bir temsili olarak sunulmaktadır. Posterde, savaşın bașında kullanılan propaganda posterlerinde olduğu gibi "ABD ordusu Koreli sivillere zarar vermektedir" şeklinde propaganda miti inşa edilmeye çalışılmaktadır. Bu amaçla posterde ABD ordusu, zulüm ve saldırı; Koreli siviller esaret ve savunma soyut kavramları üzerinden somutlanmaktadır. Posterdeki yazılı kodlar üzerinden de savaşın sonlanmasına ve barışın korunmasına çağrı yapılmaktadır. Bu aşamada Çin propagandası $\mathrm{ABD}$ ordusunu barışı bozan, Çin ordusunu da barışı sağlayan taraf olarak yansıtmaya çalışmaktadır. Çin yönetimi bu süreçte Çin ordusunun savaşa müdahalesini hem Çin'de hem de uluslararası alanda meşru kabul ettirmeyi hedeflemektedir.

Tablo 5. "Barrş" Konulu Propaganda Posteri

\begin{tabular}{ccc}
\hline & Somut Kavramlar & \\
\hline ABD ordusu & & Koreli siviller \\
\hline & Soyut Kavramlar & \\
\hline Zulüm & Esaret \\
Saldırı & Savunma \\
\hline
\end{tabular}

\section{Emperyalizm" Konulu Propaganda Posteri}

1953 tarihli "Emperyalizm" konulu propaganda posterinin tasarımcıs1 Ni Gengye'dir. Posterde Çin ve Kuzey Kore ordularının, ABD kuvvetlerine karşı vermiş olduğu mücadele yansıtılmaktadır. Posterde Çin askerlerinin, $\mathrm{ABD}$ ordusuna karşı üstünlük sağladığı ve ABD askerlerinin geri çekildiği aktarılmaktadır. ABD askerlerinden birinin beyaz mendil sallayarak teslim olduğu belirtilmektedir. Posterde "Amerikan Emperyalizminin Kıyamet Günü" yazılı kodu bulunmaktadır. 


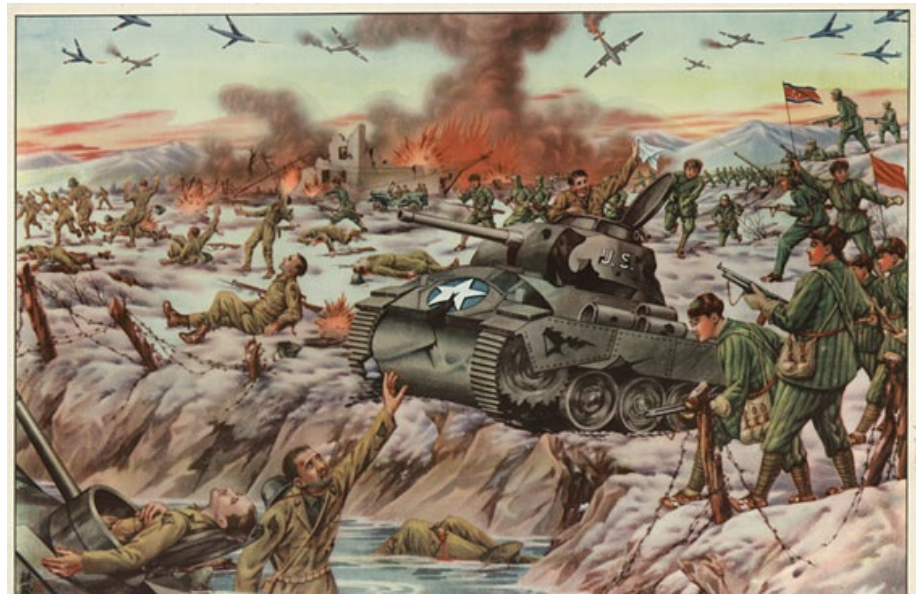

Resim 6. "Emperyalizm" Konulu Propaganda Posteri

Propaganda posteri savaşın son yılında hazırlanmıştır. Posterde Çin ve Kuzey Kore ordularının işbirliği içerisinde savaşarak ABD kuvvetlerini bozguna uğrattığı aktarılmaktadır. Bu aşamada ABD ordusu işgalci, Çin ve Kuzey Kore ordusu ise vatanlarını savunan kahramanlar olarak posterde sunulmaktadır. Görsel kodlar içerisinde Çin ve Kuzey Kore ordularının kararlı bir şekilde savaştı̆̆ı, buna karşın ABD askerlerinin teslim olduğu veya savaştan kaçtı̆̆ yansıtılmaktadır. Bu aşamada posterlerde Çin ve Kuzey Kore ordusunun zafer ve saldırı; ABD ordusunun ise hezimet ve kaçı̧ gibi soyut kavramlar üzerinden somutlandığı ortaya çıkarılmaktadır. Posterde bu şekilde "ABD, Kore Savaşı'nı kaybetti" şeklinde propaganda miti oluşturulmaya çalışılmaktadır. Böylece Çin ve Kuzey Kore ordularının daha kararlı ve daha inançlı savaşmalarının teşvik edilmesi hedeflenmiştir. Posterdeki yazılı kodlar üzerinden ABD'nin sözde emperyalist bir güç olduğuna vurgu yapılmakta, böylece Kore Savaşı'nın asıl nedeninin emperyalizm ile komünizm savaşı olduğu aktarılmaktadır. Çin propagandası bu nedenle ABD'ye karşı yalnızca Kuzey Kore'nin değil, komünizm ideolojisine inanan herkesin destek vermesini istemektedir.

Tablo 6. "Emperyalizm" Konulu Propaganda Posteri

\begin{tabular}{ccc}
\hline & Somut Kavramlar & \\
\hline Çin ordusu & ABD ordusu \\
\hline & Soyut Kavramlar & \\
\hline Zafer & Hezimet \\
Saldırı & Kaçı̧ \\
\hline
\end{tabular}

Tartışma, Sonuç ve Öneriler

Çalışmada incelenen propaganda posterlerinde, Çin yönetiminin doğrudan ABD'ye yönelik Çin kamuoyunda nefret söylemi inşa etmeye çalıştığı gözlemlenmiştir. Diğer yandan Çin yönetimi uluslararası alanda Kore Savaşı'na müdahalesini meşrulaştırmak için ABD karşıtı söylemlere yönelmiştir. Bu amaçla propaganda posterlerinde ABD ordusu zulüm, ölüm, katliam, yağma; Koreli siviller ise masumiyet, hüzün, esaret, yaşam gibi soyut kavramlar üzerinden somutlandığı ortaya çıkarılmıştır. Bu süreçte Çin ordusu kendisini Koreli sivilleri kurtarmak için harekete geçen "kahramanlar" olarak posterlerde yansıtmaya çalışmıstır. Lévi-Strauss'un İkili Karşıtlıklar Modeli'nde yer alan bir kültürün kendisini diğerlerine göre üstün görme olgusunun, Çin propagandası tarafindan doğrudan Çin ordusu üzerinden inşa edildiği ortaya çıkarılmıştır. Çin kendisine karşıt olarak da doğrudan ABD'yi hedef göstermiştir. Böylece Çin propagandası savaşın meşruluğunu sağlayarak hem Çin halkından hem de uluslararası alandan destek almaya çalışmıştır.

Çin propaganda posterlerinde ABD'nin Koreli sivilleri katlettiği ve ülkeyi büyük bir yıkıma uğrattığ1 algisının oluşturulmaya çalışıldığı görülmüştür. Bu süreçte "Amerikan ordusu Kore'de sivil halka katliam yapmaktadır" ve "ABD ordusu Koreli sivillere zulmediyor" şeklinde propaganda mitleri inşa edilerek, ABD'nin Kore'ye barıştan ziyade yıkım getirdiği yönünde mesajlar vermiştir. Çin, Kore Savaşı'na müdahil olduktan sonra da propagandasını ABD'nin savaşı kaybettiği yönünde kurgulamaya başlamıştır. $\mathrm{Bu}$ aşamada Çin propagandası tarafindan "ABD, Kore Savaşıı'nda komünist güçler tarafindan yenilgiye uğratıldı" ve "ABD, Kore Savaşı'nı kaybetti" şeklinde propaganda mitleri oluşturulmuştur. Çin 
propagandası tarafindan oluşturulan propaganda mitleri, ABD'nin Kore'ye müdahalesinde haksız olduğunu ve yaptığ1 sözde yıkımlardan dolayı da savaş1 kaybettiğini aktarmıştır. Son olarak Çin propaganda posterlerinde Çin halkının ve ordusunun Kore Savaşı'na kararllılkla destek verdiğini anlatan mesajlara yönelindiği görülmüştür. Böylece Çin yönetiminin Çin halkını zorla savaşa soktuğu algısının ortadan kaldırılması amaçlanmıştır. Posterlerde yalnızca Çincenin kullanılması, propaganda mesajının yalnızca Çin'e yönelik olduğunu göstermektedir. Bu açıdan Çin propagandasının uluslararası olmaktan ziyade ulusal bir nitelik taşıdığı ortaya çıkmaktadır.

Çalışma sonucunda, Çin ve ABD arasında 1950 yllında başlayan Kore Savaşı'ndaki gerilimin doğrudan propaganda posterlerine yansıdığı ve Çin propagandası tarafindan posterler üzerinden Çin kamuoyunda güçlü bir ABD karşıtlığının inşa edilmeye çalışıldığı ortaya konulmuştur. Çin yönetimi özellikle komünizm ideolojisini posterlerde yüceltirken, ABD'nin liderliğini yaptı̆̆ı emperyalizmi de ağır bir şekilde eleştirmiştir. Bu aşamada çalışmada Çin propagandasının kendisini ve komünizm ideolojisini ikili karşıtlıklar bağlamında yücelten söylemlere yer verdiği, ABD ve emperyalizmi ise tehlikeli olarak yansıttı̆̆1 sonucuna ulaşılmıştır.

Çalışma kapsamında Kore Savaşı sırasında Çin propagandası tarafından kullanılan propaganda posterlerinde ABD'nin nasıl ve ne şekilde sunulduğu ortaya konulmaya çalışılmıştır. Bu şekilde Kore Savaşı döneminde Çin-ABD ilişkilerine ışık tutulması amaçlanmıştır. Gelecek çalışmaların Çin'in farklı dönem ve ülkeler ile yaşadığı krizlerin propaganda posterlerine yansımasını, mevcut çalışmadaki veriler ile karşılaştırmalı olarak incelemesi alana katkı sağlayacaktır.

\section{Etik Beyan}

“Kore Savaş1 Ekseninde ABD-Çin İlişkilerinin Çin Propaganda Posterleri Üzerinden Analizi” başlıklı çalışmanın yazım sürecinde bilimsel, etik ve alıntı kurallarına uyulmuş; toplanan veriler üzerinde herhangi bir tahrifat yapılmamış ve bu çalışma herhangi başka bir akademik yayın ortamına değerlendirme için gönderilmemiştir.

\section{Kaynakça}

Barme, G. (2016). Shades of Mao: The posthumous cult of the great leader. Routledge.

Cathcart, A. (2010). Japanese devils and American wolves: Chinese communist songs from the war of liberation and the Korean War. Popular Music and Society, 33(2), 203-218.

Chen, J. (2010). Mao's China and the cold war. United States of America: Univ of North Carolina Press.

Cumings, B. (2010). The korean war: A history. The United States: Modern Library.

Cushing, L., \& Tompkins, A. (2007). Chinese posters: Art from the great proletarian cultural revolution. The United States: Chronicle Books.

Çakı, C. (2018a). İkinci dünya savaşı'ndaki propaganda savaşlarında çizgi filmin rolü: Nazi Almanyası ve Amerika Birleşik Devletleri üzerine inceleme. Halkila İliskiler ve Reklam Calışmalar E-Dergisi, 1(2), 51-63.

Çakı, C. (2018b). Adolf Hitler'in kült lider inşasında kullanılan propaganda posterlerinin göstergebilimsel analizi. Abant Kültürel Arasttrmalar Dergisi, 3(6), 24-38.

Çakı, C. (2018c). Nazi Almanyası döneminde basılan posta pullarının propaganda amaçlı kullanımı. Gümüşhane Üniversitesi İletişim Fakültesi Elektronik Dergisi, 6 (2), 1568-1595.

Domenach, J. M. (2003). Politika ve propaganda (Çev: T. Yücel), İstanbul: Varlık Yayınları.

Fiske, J. (2017). İletişim Calışmalarna giriş (Çev: S. İrvan), 5. Basım. Ankara: Bilim ve Sanat Yayınları.

Gaddins, J. L. (2018). Soğuk savaş, paz̧arlıklar, casuslar, yalanlar, gerçek (Çev: D. Cenkçiler) (3. Baskı). İstanbul: Yap1 Kredi Yayınlar1.

Gazi, M. A., Çakı, C. ve Gülada, M. O. (2018a). İkinci Dünya savaşı'nda sovyet kült lider propagandasında Vladimir Lenin ve Joseph Stalin'in sunumu. Dördüncü Kuvvet Uluslararası Hakemli Dergi, 1(2), 25-42.

Gazi, M. A., Çakı, C. ve Gülada, M. O. (2018b). İspanya 2000 Partisi'nin göçmen karşıtı propaganda faaliyetleri üzerine inceleme. Ankara Uluslararası Sosyal Bilimler Dergisi, 1(2), 11-22.

Gilbert, M. (2011). Churchill (Çev: S. Sertabiboğlu), İstanbul: Türkiye İş Bankası Yayınları.

Guiraud, P. (2016). Göstergebilim (Çev: M. Yalçın). 3. Baskı. Ankara: İmge Kitabevi.

IISH (2019). "Çin Propaganda Posterleri", https://search. social history. org/Search / Results? \&format \%3A\%22

Visual+ documents \%22\&lookfor $=$ China+ poster+ Mao+Tse-Tung, Erişim Tarihi: 21.03.2019.

Jowett, S. G. ve O'donnell, V. (2014). Propaganda \& Persuasion. USA: Sage.

Kissinger, H. (2010). Diplomasi. (Çev: İ. H. Kurt). 9. Baskı. İstanbul: Türkiye İş Bankası Yayınları.

Landsberger, S. R. (1996). Mao as the kitchen god: Religious aspects of the mao cult during the cultural revolution. China Information, 11(2-3), 196-214.

Lawrance, A. (2013). China's foreign relations since 1949. The United Kingdom: Routledge.

Leese, D. (2011). Mao Cult: Rhetoric and Ritual in China's Cultural Revolution. The United Kingdom: Cambridge University Press. 
Lévi-Strauss, C. (2012). Yapısal antropoloji (Çev: A. Kahiloğlulları). Ankara: İmge Yayınları.

Lévi-Strauss, C.(2014). Modern dünyanın sorunlar karşısında antropoloji (Çev: A. Terzi). İstanbul: Metis Yayınları.

Lévi-Strauss, C. (2017). Hepimiz Yamyamı (Çev: H. Bayrı). 2. Basım, İstanbul: Metis Yayınları.

Lévi-Strauss, C. (2018). Uzaktan Yakından (Çev: H. Bayrı). İstanbul: Metis Yayınlar1.

Lewis, J. W. ve Xue, L. (1993). Uncertain Partners: Stalin, Mao, and the Korean War (Vol. 4). The United States: Stanford University Press.

Lowe, P. (2014). The origins of the Korean war. The United Kingdom: Routledge.

Mcmahon, J. R. (2013). Soğuk savaş (Çev: S. Gül). Ankara: Dost Kültür Yayınları.

Nish, I. (2014). The origins of the Russo-Japanese war. The United Kingdom: Routledge.

Paltiel, J. T. (1983). The cult of personality: Some comparative reflections on political culture in Leninist regimes. Studies in Comparative Communism, 16(1-2), 49-64.

Powell, P. ve Wong, J. (1997). Propaganda posters from the Chinese cultural revolution. The Historian, 59(4), 777-793.

Pickowicz, P. (2010). Revisiting cold war propaganda: Close readings of Chinese and American film representations of the Korean War. Journal of American-East Asian Relations, 17(4), 352-371.

Priestland, D. (2017). Kı̨̆l bayrak bir komünizm taribi (Çev: A. Çakıroğlu ve E. Yılgür). İstanbul: İletişim Yayınları.

Rawnsley, G. D. (2009). The great movement to resist America and assist Korea: How Beijing sold the Korean War. Media, War \& Conflict, 2(3), 285-315.

Rifat, M. (2013). Açıllamalı göstergebilim sözlïğ̈̈: Kavramlar, yöntemler, kuramcılar, okullar. İstanbul: Türkiye İș Bankası Kültür Yayınları.

Sandler, S. (2015). The Korean War: No victors, no vanquished. The United States: University Press of Kentucky.

Shen, K. (2000). Publishing posters before the cultural revolution. Modern Chinese Literature and Culture, 12(2), 177-202.

Sı̆̆ırc1, İ. (2016). Göstergebilim uygulamalar, metinleri, görselleri ve olaylar okuma. Ankara: Seçkin Yayıncılık.

Stueck, W. (1997). The Korean War: an International History (Vol. 68). The United States: Princeton University Press.

Stueck, W. (2013). Rethinking the Korean War: A New Diplomatic and Strategic History. The United States: Princeton University Press.

Tarhan, N. (2010). Psikolojik savas, gri propaganda (13. Bask1). İstanbul: Timaş Yayınları.

Yufan, H., \& Zhihai, Z. (1990). China's decision to enter the Korean War: History revisted. The China Quarterly, 121, 94-115.

Xing-Hua, L. (2005). Political representation within the libidinal economy of a pictorial space: A political-semiotic reading of three propaganda posters of the chinese cultural revolution. Semiotica, 2005(157), 213-232.

Xia, Y. (2014). The people's republic of China. Ashgate Research Companion to the Korean War, 61-72.

Yang, G. M. ve Suchan, T. (2009). The cultural revolution and contemporary Chinese art. Art Education, 62(6), 25-32.

\section{EXTENDED ABSTRACT}

The Korean War began as a regional conflict between North Korea and South Korea on June 25, 1950. In spite of this, the war with the intervention of the US and its allies against North Korea became an international dimension. The coalition forces led by the United States obtained a big victory against North Korea and approached the Chinese border. Whereupon The People's Republic of China sent hundreds of thousands of soldiers to North Korea on 25 October 1950. China's intervention in the war led to a change in the balance of war and the withdrawal of coalition forces. In the following stage, both sides had no advantage over each other. In this process, China engaged in intense propaganda against the United States and tried to maintain the support of the Chinese people in the war. One of the most common mass media tools of Chinese propaganda at this stage was the posters. In the context of the study, how and in what way Chinese propaganda posters were used to create anti-US public opinion during the Korean War was examined by using semiotic analysis.

The main aim of the study is to reveal Chinese-USA relations through posters used by Chinese propaganda in the Korean War. As a result of extensive literature review in national academic studies, academic studies on the propaganda activities of the People's Republic of China couldn't be found. In this respect, it was aimed to contribute the field with the current study. On the other hand, the study is important because it gives information about Chinese-USA relations in the Korean War and its role in international relations.

In the Korean War, the sample was used in the study because of the difficulty of examining all propaganda posters prepared by Chinese propaganda. For this purpose, six propaganda posters were used in the study. The Chinese propaganda posters analyzed in the study were selected from the International Institute of Social History (IISH).

In this study, the analysis of only the six Chinese propaganda posters and the generalizations within the scope of the findings are the main limitations of the study. 
The aim of the study was to find answers to the following questions;

In posters used by Chinese propaganda during the Korean War;

- what are the basic propaganda messages?

- which negative concepts were used for the US?

- which propaganda myths against the USA were tried to be built?

In the study, semiotic analysis method in the qualitative research methods was used. The propaganda posters determined within the scope of the study were analyzed by the French Anthropologist Claude Lévi-Strauss's Binary Contrasts Model. In particular, it was tried to reveal which abstract concepts represented the USA in propaganda posters. In the propaganda posters examined in the study, it was observed that the Chinese government tried to build hate speech directly to the US public opinion in China. On the other hand, the Chinese administration turned to anti-USA rhetoric to justify its intervention in the Korean War on the international area. In this process, the Chinese army tried to reflect itself in the posters as heroes who acted to save Korean civilians.

It was observed that the Chinese propaganda posters tried to form the perception that the US massacred Korean civilians and destroyed the country. In this process, propaganda myths such as "the US army massacred civilians in Korea," and "the US military persecuted Korean civilians" were constructed. After China joined the Korean War, China began to spread its propaganda in the direction that the US lost the war. Lastly, it was seen that Chinese propaganda posters directed the messages that the Chinese people and the army strongly supported the Korean War. Thus, it was aimed to eliminate the perception that the Chinese administration forced the Chinese people into war.

As a result of the study, it was revealed that the tension in the Korean War, which started in 1950 between China and the USA, was reflected in direct propaganda posters and that a strong anti-US opposition was tried to be built by Chinese propaganda through Chinese posters. While the Chinese administration especially praised the ideology of communism in posters, it heavily criticized the US-led imperialism. At this stage, it was concluded that the Chinese propaganda reflected USA and imperialism as dangerous. Within the scope of the study, it was tried to show how and in what way the USA was presented in the propaganda posters used by Chinese propaganda during the Korean War. In this way, it was aimed to shed light on the Chinese-USA relations during the Korean War. 